\title{
Academic Self-Concept and Critical Thinking Dispositions: Devising a Predictive Model of College Students' Degree Commitment
}

\author{
Marios Dimitrios Chatzinikolaou* and Andreas Tsirides
}

Department of Psychology, University of Derby, United Kingdom

\section{ARTICLE INFO}

\section{Keywords:}

Academic success

College attrition

Educational psychology

Higher education

Student retention

\begin{abstract}
Educational researchers incessantly endeavor to address underlying reasons for academic success/failure, and Degree Commitment constitutes a critical sought-after academic outcome regarding college students, which is considerably associated with higher student retention rates. Educational institutions may create effective preventive strategies and interventions for minimizing attrition issues by identifying factors leading to higher Degree Commitment. The aim of the current research was to explore the potential predictive relationship between higher demonstration of college students' Academic Self-Concept and higher levels of Critical Thinking Dispositions on their commitment of further pursuing their chosen degree. A questionnaire-based survey method was employed, adopting a correlational design on a recruited purposive sample of 120 Greek college students of a privately-owned educational institution. A multiple regression statistical analysis generated a weak positive correlation (9.2\%) between the predictors, with Academic SelfConcept being the strongest predictor of Degree Commitment, implying that the combination of the aforementioned academic facets significantly predicts Degree Commitment, but with a small generalization explanatory power to a population sharing common characteristics with the utilized sample. Although the devised model is of minimal practical use, it proposes an initial attempt to construct a holistic model of academic success, while simultaneously highlighting the necessity for developing interventions that robustly target Critical Thinking Dispositions and, most importantly, Academic Self-Concept. Future research may explore factors influencing the predictors under investigation, compare them between students deriving from traditional educational systems and those deriving from international educational systems, and explore alternative factors concerning college success and attrition within various sociocultural contexts.
\end{abstract}

\section{Introduction}

Determining factors of success in higher education have concerned psychological and educational researchers for many decades, as understanding psychosocial factors along with study skills, their relations and effect over academic success, and performance is of great importance for theoretical but also practical reasons (Robbins, et al., 2004). A few investigations have previously reported that only $44 \%$ of students complete their 4 -year studies and earn a degree (Tinto, 1993; Youn, 1992), with 75\% of them departing from college within the first 2 years, while the greatest proportion does so after the first year (Tinto, 1993). Remarkably, within the Greek higher education setting, low ranges of academic retention have been observed among the Organization for Economic Co-operation and Development countries (OECD, 2019). For instance, from all engineering students enrolled at the National Technical

*Corresponding author E-mail address: chatzinikolaou.marios-dimitrios@outlook.com 
University of Athens (Caroni, 2011), only 27\% of those registered in the years 1992-2003 reached graduation following the nominal 5-year studies, and a percentage of approximately $12 \%$ is predicted to perpetually remain in college. Thus, the imperative necessity of investigating factors leading to higher commitment to a chosen degree may lead to more effective attrition preventive strategies.

\subsection{Degree Commitment}

Degree commitment (DC) is qualified as a major sought-after outcome with regards to college students and has been extensively researched and discussed (Hill et al., 2016). The interchangeable utilization with academic terminology (college persistence, college student retention) has further revealed its relevance to the concept of attrition. Tinto's (1993) student integration model described attrition as a long-term, interactive process, affected by diverse factors ranging from student's aspirations, intentions, purposes, and sense of commitment (Sharma \& Yukhymenko-Lescroart, 2018). Relevant research additionally highlights the positive correlation between one's aspirations devotion and purpose confidence on college persistence (Staples \& Troutman, 2010). Besides, Davidson and colleagues' (2015) research findings underlined the observable relationship between DC and students' institutional commitment, academic and social integration, academic efficacy, motivation to learn, conscientiousness, and standardized test scores.

\subsection{Critical Thinking Dispositions}

A vital academic facet regarding the development of student critical attitude, necessary for effective decision-making, is critical thinking (Stapleton, 2010). Although not clearly defined, research coalesces its composition of two fundamental dimensions; the cognitive (skills) and dispositional (propensity) one (Facione et al., 1995; Fasko, 2003), adding elements of reflective skepticism and mental activity engagement, therefore constituting it a higher order thinking skill (Johnson, 2002). Its cognitive aspect revolves around intellectual abilities (reasoning/logical thinking) (Arifin et al., 2019), whereas its dispositional one concentrates on individuals' inclination to employ possessed attributes and personal characteristics (critical openness and intellectual talents) (Clifford et al., 2004) that can consequently describe individuals' decision-making, arguing and reasoning processes (Perkins et al., 1993). According to Norris (2003), intellectual abilities precede and further coexist with dispositions. However, evidence has not yet supported this allegation, while the opposite, namely the disposition preceding the actual manifestation of intellectual skills, has been widely researched (Ku \& Ho, 2010; West et al., 2008). Several investigations positively supplementarily associate critical thinking dispositions (CTD) to academic performance, professionalism, resilience, reasoning, and in-depth learning (El-sayed et al., 2011; Fahim et al., 2010; Macpherson \& Stanovich, 2007). Thus, their significance in higher education is well-ascertained, as thinking critically and functioning proficiently may be a prerequisite for effective decision-making regarding an individual's academic path (e.g., committing to following a preferred degree) (Stewart \& Dempsey, 2005).

Transitioning from school education to higher education requires critical thinking development as a higher cognitive order, along with knowledge application within various contexts (Wingate, 2007), which is observed within certain educational programmes like the International Baccalaureate Diploma Programme (IBDP), effectively promoting student critical attitude (Cole et al., 2014). However, several students in different educational settings lack the necessary understanding of higher education entailments (Gamache, 2002), needing guidance to construct their knowledge and integrating it efficiently within their study discipline (Lea \& Street, 1998). Interesting findings by Byrne et al. (2012) suggest that, compared to Irish and UK students, Greek and Spanish students deem their traditional school preparation 
inadequate for easing their transition into university/college, an independent learning environment. In Greece's educational system, the underdeveloped skill of critical thinking in formal setting was introduced in 1980 (Theodosiadou, 2012), yet its development in students is considered a challenge rather than an achieved goal, even 26 years later (Matsagouras, 2006). Thereupon, exploring college students' own dispositions towards critical thinking (as a precondition for effectively developing critical thinking skills) may be decisive in unravelling their factorial correlation with DC.

\subsection{Academic Self-Concept}

Academic self-concept (ASC) is another area of individual differences impacting and defining students' present and future aspirations (Dunkel et al., 2010), and has been found to strongly affect their commitment to their chosen degree (Demetriou \& Schmitz-Sciborski, 2011; Jung, 2013, 2012; Haktanir et al., 2018). ASC notion is a rather multifaceted one, encompassing individuals' self-perception, reflection, and sense of evaluation regarding their academic competences and views on their academic abilities in contrast to other students (Smith, 2019; Tight, 2019; Byrne \& Shavelson, 1986). Lent and colleagues (1997) maintain that ASC is also a representation of one's self-feelings and beliefs concerning college adjustment, in conjunction with evaluation of others' judgments of them (DeFreitas \& Rinn, 2013). Thus, a universal definition is rather difficult, as the construct is often approached from different theoretical viewpoints (Ahmed \& Bruinsma, 2006; Sánchez \& Roda, 2003).

Interestingly, in relevant studies (Jacob et al., 2002), individuals' ASC may dwindle following the transition from mid-adolescence to adulthood, complementing their academic achievement levels (Awad, 2007), thus hypothesizing to impact their commitment levels to the chosen higher education study field (Liu \& Wang, 2005; Matovu, 2017). In Greece, adolescent selfconcept has been investigated along with its relation to academic competence, revealing that teenagers' self-concept of their ability to achieve high academic performance is particularly low, especially in subjects such as mathematics (Kiritsis, 2016). However, as of today, no studies have been conducted regarding college students' ASC in the Greek college reality.

\subsection{Aims and Objectives}

Since most research mainly employs socioeconomic perspectives regarding higher education costs/benefits (Cabrera \& La Nasa, 2000; Perna, 2006; Jung, 2013), it is important to further robustly target specific academic elements predicting college students' commitment towards their chosen degree. Correspondingly, as college students in Greece constitute a subculture within the broader Greek educational culture, not exhibiting satisfactory levels of critical thinking (Matsagouras, 2016; Byrne et al., 2012) and not being aware of their ASC levels or their possible ramifications, the present study employs the notions of ASC and CTD as predictors of DC, aiming at exploring their combinational predictive force, which has not been previously explicitly examined. In addition, an examination of the current literature reveals numerous multi-predictor models that attempt to predict college retention, with the outcome being a sum of many factors. To our knowledge, no attempt has been made to devise a model using solely ASC and CTS as predictors for DC. Consequently, the purpose of this study is to devise a model of prediction of degree commitment, based on 2 student-related traits, using a minimalistic set of questions.

The hypothesis for this research is that higher demonstration of students' ASC and higher levels of students' CTD will predict stronger students' commitment concerning their pursuit of a degree. 


\section{Method and Materials}

\subsection{Design}

A questionnaire-based survey method was employed, adopting a correlational design. The first predictor was Academic Self-Concept, and the second predictor was students' Critical Thinking Dispositions, while the outcome measured was Degree Commitment. All variables were of at least interval level of measurement.

\subsection{Participants}

An a priori power analysis, using the $\mathrm{G}^{*}$ Power software (Faul et al., 2007) recommended a minimum sample size of 107 participants. To that end, 120 Greek college students of a privately-owned educational institution (63 Females, 54 Males, 3 Prefer Not to Say, $M=23.25$, $\mathrm{SD}=6.67$ ), aged 18-49 years, from various academic fields (Business, Computing, Education, Engineering, Health \& Sport Sciences, Psychology, Shipping, Tourism \& Hospitality) were recruited through purposive sampling. Inclusion criteria stipulated that participants should fulfill the following requirements; (a) be undergraduate College students, (b) be above 18 years of age, (c) be able to effectively communicate in English. Participants with hearing/visual deficiencies were excluded from the research, along with those having any kind of cognitive dysfunction.

\subsection{Materials}

This research made use of 3 fundamental instruments, which were compiled and used in a single 5-point Likert scale form ( 1 = Completely Disagree, 5 = Completely Agree $)$, directly measuring the predictors under investigation; (a) the Academic Self-Concept Scale (ASCS) (Liu \& Wang, 2005); a valid and reliable (Cronbach's $\alpha=.753$ ) 20-item questionnaire consisting of 2 first-order factors; academic confidence and academic effort. It includes statements such as using statements like "If I work hard, I think I can get better grades". Following that, the Critical Thinking Disposition Scale (CTDS) (Sosu, 2013), an 11-item instrument with good psychometric properties (Cronbach's $\alpha=.751$ ) measuring 2 factors, namely reflective skepticism and critical openness, and including statements such as "I am often on the lookout for new ideas". Lastly, the seventh factor of the College Persistence Questionnaire Test-Version 3 (CPQT3) (Davidson et al., 2009), which is DC, was employed. CPQT3 is a 9-factor, 81 -item questionnaire with proven validity and reliability (Cronbach's $\alpha$ $=.541$, and despite being thus far utilized in its entirety, this research aims at targeting the DC factor directly, not having been separately investigated by previous research. It uses statements like "At this moment in time, I would say my commitment to earn a college degree here or elsewhere is strong", and some items were reversed in order to minimize the possibility of repetitive or random answers. The IBM Statistical Package for the Social Sciences (version 25.0) was employed for data screening and analysis, as well as the G*Power software (Faul et al., 2007) for sample size calculation, and all necessary briefing/consent/debriefing forms were distributed to all participants.

\subsection{Procedure}

Following the ethical approval by the scientific committee of the University of Derby and by the team's supervisor, participants were informed about the study through an announcement (via e-mail) from the administration office of their educational institution. The study was conducted at the building's premises, at a designated time, on a weekday. All attending participants were given the briefing and consent forms at the beginning of the study, according to the British Psychological Association (BPS) ethics code. Following their signing them, the compiled questionnaire was distributed to them. After that, participants subsequently received 
the debriefing notes. All responders returned their questionnaires filled-in, thus the $N>72$ criterion for a conservative $\mathrm{R}^{2}=0.15$ with power $=0.80$ was fulfilled.

\section{Results}

\subsection{Parametric Assumption Testing}

The eligibility of the parametric assumptions was investigated prior to conducting the appropriate inferential statistical analysis (see Table 1 for correlations). Initially, the parametric assumption of the outcome being at the interval scale of measurement was met. Subsequently, no outliers were detected within the dataset (+/-3 criterion) when transforming the scores to $\mathrm{Z}$ scores. Although further observations of the Q-Q plots and Boxplots revealed multiple potential outliers, these participants did not deviate from the symmetrical distribution, having nonconcerning/alarming z scores values.

Table 1.

Correlation Table (Correlation Coefficients \& Significance Levels) for the Predictors and the Outcome

\begin{tabular}{lcc}
\hline & Academic Self-Concept & Critical Thinking Dispositions \\
\hline Degree Commitment & $0.281(=0.001)$ & $0.217(=0.009)$ \\
Academic Self-Concept & & $0.4(<0.001)$ \\
\hline
\end{tabular}

The Kolmogorov-Smirnov normality test indicated that approximate normal distribution was attained for ASC $[D(120)=0.058, p=0.2]$, but not for CTD $[D(120)=0.096, p=0.009]$ and DC $[D(120)=0.121, p<0.001]$. Additionally, the Shapiro-Wilk normality test revealed a normal distribution for ASC $[W(120)=0.991, p=0.666]$, but not for CTD $[W(120)=0.977, p=0.037]$ and $\mathrm{DC}[W(120)=0.961, p=0.002]$. Complementary inspection of the skewness and kurtosis scores revealed non-alarming values $(+/-2.58$ criterion for sample sizes of $101-200, N=120)$. Normal distribution of the regression residuals was accepted, due to the application to a linear regression model (Li et al., 2012). Final observations of the histograms revealed non-accurately displayed graphs, attributed to the relatively small sample size used $(N=120<200)$. The assumption of independent errors was subsequently met (Durbin-Watson value $=2.410$ ), and no multicollinearity issues were indicated within the data [Academic Self-Concept (Tolerance $=0.840, \quad V I F=1.191$ ); Critical Thinking Dispositions (Tolerance $=0.840$, $V I F=1.191)]$.

\subsection{Multiple Regression Analysis}

The data was analyzed by utilizing a multiple regression inferential statistical analysis, with the use of the Enter Method. The regression equation generated a small-to-medium effect size ${ }^{1}$ $\left(R^{2}=0.092, R_{\text {Adjusted }}^{2}=0.076\right)$ and a weak positive correlation between the model's predictors was produced $(R=0.303)$. Hence, higher demonstration of academic facets (ASC and CTD) can significantly predict greater commitment towards a degree $[F(2,117)=5.916, p=0.004<\alpha$, alpha $=0.05 \div 2=0.025$, one-tailed]. More specifically, there was a significant positive relationship between ASC and DC $(t=2.398, d f=119, p=0.018<\alpha$, alpha $=0.05 \div 2=0.025$, onetailed), and the regression model predicts that one-unit change in ASC will result in 0.333 levels of DC. This was further observed/interpreted by the regression line equation $(y=2.55+0.41 \times x)$, in which the replacement of the $\mathrm{x}$ value with any of the graph's $\mathrm{x}$-axis

\footnotetext{
${ }^{1}$ Based on Cohen's (1988) guidelines:

$0.02($ or $2 \%)=$ Small

$0.13($ or $13 \%)=$ Medium

$0.26($ or $26 \%)=$ Large
} 
interpolated values (i.e. ASC) predicts the value position within the interpolated y-axis (i.e. DC). Oppositely, there was a non-significant positive relationship between CTD and DC $(t=1.3, d f=119, p=0.196>\alpha$, alpha $=0.05 \div 2=0.025$, one-tailed $)$.

\section{Discussion}

A multiple regression inferential analysis was employed to explore whether college students' higher demonstration of ASC and higher demonstration of CTD would predict higher DC levels. The hypothesis was partially confirmed by the results, revealing a significant relationship between the conjunction of the two predictors and the proposed outcome. Put differently, ASC and the presence of CTD can significantly predict higher levels of DC. Yet, the generated effect's magnitude percentage was small-to-medium, suggesting that only $0.09 \%$ of the variance in DC levels is explained by ASC and CTD. The regression model showed a $0.08 \%$ generalization explanatory power to a population sharing common characteristics with the utilized sample. Thus, despite the statistical significance of the results, it seems that the proposed model has minimal practical application.

Higher levels of ASC predicted greater DC, in line with recent findings by Haktanir et al. (2018) who suggested that college adjustment, indirectly leading to DC, is affected by a diverse array of factors, including ASC. Nonetheless, these findings are novel to the Greek setting, where ASC had not been previously linked to the notion of DC. The present findings further confirm the notion that ASC can be viewed as an individual difference impacting college students' future aspirations, particularly pursuing their chosen degree (Liu \& Wang, 2005; Dunkel et al., 2010; Demetriou \& Schmitz-Sciborski, 2011; Jung, 2013; Matovu, 2017). It is difficult to ascertain whether the levels of ASC have indeed decreased following the transition to higher education as the study focused on tertiary education students (Jacob et al., 2002; Awad, 2007).

In light of the present research findings, CTD is a significant predictor of student retention, but only when combined with high demonstrated levels of ASC. This may illustrate that both predictors share a cognitive element, yet the weakness of generating predictions concerning academic success in its entirety may constitute CTD a non-prerequisite for effective decision-making reflected by students' DC, as was previously maintained by research (Stewart \& Dempsey, 2005). Nonetheless, the deduction of CTD facilitating students' academic decision-making is evident, as their combination with another academic facet generates significant predictions.

The findings produce contradictions regarding whether critical thinking's nature is primarily a disposition or a cognitive perspective, as indicated by previous research (Facione et al., 1995; Fasko, 2003). Intellectual abilities, as a cognitive aspect of critical thinking, is also an overarching concept, encompassing cognitive functions such as decision-making; such processes have already been allegedly indirectly linked to DC (Stewart \& Dempsey, 2005). Although research has shown that dispositions may precede the manifestation of critical thinking skills (Ku \& Ho, 2010; West et al., 2008), CTD solely could not predict DC, hence deducing that they may not precede the skill (e.g., effective decision-making processes linked to DC), generating non-significant predictive power over the suggested outcome. Furthermore, implementation of findings within the Greek setting neither confirm nor invalidate relevant research highlighting that critical thinking is still a challenge for Greek college students (Matsagouras, 2006; Theodosiadou, 2012), as their dispositions towards thinking critically were relatively high, not necessarily correlating to the cognitive perspective of critical thinking or presupposing the acquisition of the relevant skills (Facione et al, 1995; Norris, 2003).

Noteworthily, contrary to previous findings regarding college student retention rates in Greece (OECD, 2019; Caroni, 2011), the results of the questionnaires revealed a tendency of students' positive intentions towards the completion of their degree. Further exploration is required, however, as participants have selectively chosen to undertake that commitment, possibly 
predisposing themselves into believing they should possess a commitment towards earning their chosen degree. It should also be noted that the fact that the questionnaires were distributed inside their educational institution may have led to biased answers.

\subsection{Strengths and Limitations}

The research was short and cost-effective, hence easily replicable. A post-hoc power analysis was further performed, indicating a strong achieved power of the regression model (0.80), hence there was significant power at the small-to-medium effect size level and a sufficient sample size was employed. Additionally, questionnaire bias was attempted to be eliminated by conducting reliability analyses to investigate the internal consistency of the utilized scales' items. Overall, the ASCS indicated an acceptable internal consistency $(\alpha=0.753)$. Several items revealed Item-Total Correlation values below optimal $(r<0.2)$, thus the subsequent exclusion of four questions (ASCS4_Reversed, ASCS5, ASCS7_Reversed, ASCS19) improved the overall internal consistency $(\alpha=0.772$, then $\alpha=0.780$, then $\alpha=0.799$, then $\alpha=0.8)$ of the scale. The CTDS similarly indicated an acceptable internal consistency $(\alpha=0.751)$ and, since one item revealed an Item-Total Correlation value below optimal $(r<0.2)$, it was sequentially removed (CTDS7) to slightly improve the scale's overall internal consistency $(\alpha=0.776)$.

Certain limitations, however, need to be addressed. Although the questionnaires were multifactorial, they consisted of a small number of factors. Therefore, the analysis did not include other uninvestigated aspects of ASC and CTD. Likewise, the self-reporting nature of the instruments may, to a certain extent, have stipulated answers in exhibiting social desirability biases, as mentioned above. Still though, students' positive tendencies towards academic facets and DC cannot be necessarily characterized as social desirability biases, since they may candidly believe in having acquired such fundamental academic skills. The devised questionnaire was handed out in English language, as participants were considered Englishspeaking. However, it has been originally devised for foreign cultures, thus, regardless the language comprehension ability, the validity of the instrument may have been compromised, as the current cultural context is different from the original in terms of culture, time and localization. Also, one of the questionnaires was an extracted factor, hence it may also have some impact in validity, by means of functioning differently outside its original context.

\subsection{Implementations and Future Directions}

The results have practical implications for education, revealing a need for interventions on college students in Greece to improve their levels of ASC, being a strong predictor of their commitment to their chosen degree and also investigate factors affecting college students' ASC. In fact, educators may integrate Academic Self-Concept and Critical Thinking Dispositions into a holistic learning plan that will facilitate the needs of all students. Randomized controlled trials might be employed to evaluate interventions employed to increase the levels of individuals' ASC. Furthermore, given that certain international educational systems such as the IBDP have been linked to higher levels of student critical thinking (Cole et al., 2014), it is recommended that future research may focus on cohorts of IBDP and non-IBDP students transitioning to higher education to further explore their CTD and their relation to DC and possibly associate it with the viewpoint of attribution theories.

\section{Conclusion}

In conclusion, this study was an initial attempt to devise a predictive model in order to explore possible factors that may explain student attrition for privately owned colleges in Greece. Results from this study should be interpreted cautiously as data were gathered from a sample of students at a single college and in a particularly short period of time. 
Regardless of the minimal practicality of the devised model, due to the small variance of the outcome explained by the predictor, it follows a methodological path based on previous research that may be exploited for future studies. More than $90 \%$ of the variance may be explained by different variables than the ones used, thus there is more than adequate space for exploration with many other variables indicated from current literature, larger samples from different institutions, using instruments adjusted to current sociocultural context in terms of time, locality and language.

\section{Acknowledgements}

We would like to express our profound respect and gratitude towards our research supervisor, Dr. Penelope Louka, who provided us with valuable insight throughout the whole project and for assisting us in clearly articulating our thoughts within this paper. Also, once again, we wholeheartedly and truthfully thank those who took part in our research.

\section{Abbreviations}

Degree Commitment: DC

Critical Thinking Dispositions: CTD

Academic Self-Concept: ASC

\section{References}

Ahmed, W., \& Bruinsma, M. (2006). A Structural Model of Self-concept, Autonomous Motivation and Academic Performance in Cross-cultural Perspective. Electronic Journal of Research in Educational Psychology, No. 10, 4(3), 551-576.

Arifin, Y., Setyosari, P., Sa'dijah, C., \& Kuswandi, D. (2019). Increasing Critical Thinking and Student Retention: A Learning Model Approach. International Journal of Research and Review, 6(10), 168-175.

Awad, G. H. (2007). The role of racial identity, academic self-concept, and self-esteem in the prediction of academic outcomes for African American students. Journal of Black Psychology, 33(2), 188-207.

Byrne, B. M., \& Shavelson, R. J. (1986). On the structure of adolescent self-concept. Journal of Educational Psychology, 78(6), 474-481.

Byrne, M., Flood, B., Hassall, T., Joyce, J., Arquero Montaño, J. L., González González, J. M., \& Tourna-Germanou, E. (2012). Motivations, expectations and preparedness for higher education: A study of accounting students in Ireland, the UK, Spain and Greece. Accounting Forum, 36(2), 134-144.

Cabrera, A. F., \& La Nasa, S. (2000). Understanding the college-choice process. New Directions for Institutional Research, 2000(107), 5-22.

Caroni, C. (2011). Graduation and attrition of engineering students in Greece. European Journal of Engineering Education, 36(1), 63-74.

Clifford, J. S., Boufal, M. M., \& Kurtz, J. E. (2004). Personality traits and critical thinking: Skills in college students empirical tests of a two-factor theory. Assessment, 11(2), 169-176.

Cohen, J. (1988). Statistical power analysis for the behavioral sciences, 2nd ed. Hillsdale, NJ: Erlbaum.

Cole, D. R., Gannon, S., Ullman, J., \& Rooney, P. (2014). Theory of knowledge (TOK): Exploring learning outcomes, benefits and perceptions. Bethesda, MD: International Baccalaureate Organization. 
Davidson, W. B., Beck, H. P., \& Grisaffe, D. B. (2015). Increasing the institutional commitment of college students: Enhanced measurement and test of a nomological model. Journal of College Student Retention: Research, Theory \& Practice, 17.

Davidson, W. B., Beck, H. P., \& Milligan, M. (2009). The college persistence questionnaire: Development and validation of an instrument that predicts student attrition. Journal of College Student Development, 50(4), 373-390.

DeFreitas, S. C., \& Rinn, A. (2013). Academic achievement in first generation college students: The role of academic self-concept. Journal of the Scholarship of Teaching and Learning, 57-67.

Demetriou, C., \& Schmitz-Sciborski, A. (2011). Integration, motivation, strengths and optimism: Retention theories past, present and future. In R. Hayes (Ed.), Proceedings of the 7th National Symposium on Student Retention, 2011, Charleston (pp. 300-312). Norman, OK: The University of Oklahoma.

Dunkel, C. S., Minor, L., \& Babineau, M. (2010). The continued assessment of self-continuity and identity. The Journal of genetic psychology, 171(3), 251-261.

El-sayed, R. S., Sleem, W. F., El-sayed, N. M., \& Ramada, F. A.(2011). Disposition of staff nurses' critical thinking and its relation to quality of their performance at Mansoura University Hospital. Journal of American Science, 7, 388-395

Facione, P. A., Sanchez, C. A., Facione, N. C., \& Gainen, J. (1995). The disposition toward critical thinking. The Journal of General Education, 1-25.

Fahim, M., Bagherkazemi, M., \& Alemi, M. (2010). The relationship between test takers' critical thinking ability and their performance on the reading section of TOEFL. Journal of Language Teaching and Research, 1(6), 830.

Fasko, D. (2003). Critical thinking: Origins, historical development, future directions. In D. Fasko (Ed.), Critical thinking and reasoning: Current research, theory and practice (pp. 318). Cresskill, NJ: Hampton Press.

Faul, F., Erdfelder, E., Lang, A.-G. \& Buchner, A. (2007). G*Power 3: A flexible statistical power analysis program for the social, behavioral, and biomedical sciences. Behavior Research Methods, 39, 175-191.

Gamache, P. (2002). University students as creators of personal knowledge: An alternative epistemological view. Teaching in Higher Education, 7(3), 277-293.

Haktanir, A., Watson, J. C., Ermis-Demirtas, H., Karaman, M. A., Freeman, P. D., Kumaran, A., \& Streeter, A. (2018). Resilience, Academic Self-Concept, and College Adjustment Among First-Year Students. Journal of College Student Retention: Research, Theory \& Practice.

Hill, P. L., Burrow, A. L., \& Bronk, K. C. (2016). Persevering with positivity and purpose: An examination of purpose commitment and positive affect as predictors of grit. Journal of Happiness Studies, 17(1), 257-269.

Jacob, J. E., Lanza, S., Osgood, D. W., Eccles, J. S., \& Wigfield, A. (2002). Changes in children's self-competence and value: gender and domain differences across grades one through twelve. Child development, 73, 509- 527.

Johnson, E. B. (2002). Contextual teaching and learning: what it is and why its here to stay. Thousand Oaks: Corwin Press. 
Jung, J. Y. (2013). Amotivation and indecision in the decision-making processes associated with university entry. Research in Higher Education, 54, 115-136.

Kiritsis, D. (2016). Self-concept and Family: A study on Greek secondary school students. Journal of Contemporary Issues in Education, 10(1).

Ku, K. Y., \& Ho, I. T. (2010). Dispositional factors predicting Chinese students' critical thinking performance. Personality and Individual Differences, 48(1), 54-58.

Lea, M., \& Street, B. (1998). Student writing in higher education: An academic literacies approach. Studies in Higher Education, 11(3), 182-199.

Lent, R. W., Brown, S. D., \& Gore, P. A., Jr. (1997). Discriminant and predictive validity of academic self-concept, academic self-efficacy, and mathematics-specific self-efficacy. Journal of Counseling Psychology, 44(3), 307-315.

Li, X., Wong, W., Lamoureux, E. L., \& Wong, T. Y. (2012). Are linear regression techniques appropriate for analysis when the dependent (outcome) variable is not normally distributed?. Investigative ophthalmology \& visual science, 53(6), 3082-3083.

Liu, W. C., \& Wang, C. K. J. (2005). Academic self-concept: A cross-sectional study of grade and gender differences in a Singapore secondary school. Asia Pacific Education Review, 6(1), 20-27.

Macpherson, R., \& Stanovich, K. E. (2007). Cognitive ability, thinking dispositions, and instructional set as predictors of critical thinking. Learning and individual differences, 17(2), 115-127.

Matovu, M. (2017). A structural equation modelling of the academic self-concept scale. International Electronic Journal of Elementary Education, 6(2), 185-198.

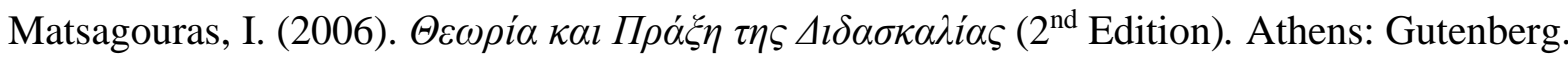

Norris, S. P. (2003). The meaning of critical thinking test performance: The effects of abilities and dispositions on scores. In D. Fasko (Ed.), Critical thinking and reasoning: Current research, theory and practice (pp. 315-329). Cresskill, NJ: Hampton Press.

OECD (2019), Education at a Glance 2019: OECD indicators, OECD Publishing, Paris.

Perkins, D. N., Jay, E., \& Tishman, S. (1993). Beyond abilities: A dispositional theory of thinking. Merrill-Palmer Quarterly, 39, 1-21.

Perna, L. (2006). Studying college access and choice: A proposed conceptual model. In J. C. Smart (Ed.), Higher education: Handbook of theory and research (pp. 99-157). Dordrecht, The Netherlands: Springer.

Robbins, S. B., Kristy, L., Le, H., Davis, D., Langley, R., \& Carlstrom, A. (2004). Do Psychosocial and Study Skill Factors Predict College Outcomes? A Meta-Analysis. Psychological Bulletin, 130(2), 261-288.

Sánchez, F. J., \& Roda, M. D. (2003). Relationships between self-concept and academic achievement in primary students. Electronic Journal of Research in Educational Psychology and Psychopedagogy, 1(1), 95-120

Sharma, G., \& Yukhymenko-Lescroart, M. (2018). The Relationship Between College Students' Sense of Purpose and Degree Commitment. Journal of College Student Development, 59(4), 486-491.

Smith, K. H. (2019). The Multi-Dimensionality of Academic Self-Concept. Educational Practice and Theory, 4l(1), 71-81. 
Sosu, E. M. (2013). The development and psychometric validation of a Critical Thinking Disposition Scale. Thinking Skills and Creativity, 9, 107-119.

Staples, J. M., \& Troutman, S. (2010). What's the Purpose?: How Urban Adolescents of Color Interpret and Respond to Noble and Ignoble Purposes Constructed in Media Texts. Journal of Urban Learning, Teaching, and Research, 6, 31-43.

Stapleton, P. (2010). A survey of attitudes towards critical thinking among Hong Kong secondary school teachers: Implications for policy change. Thinking Skills and Creativity, $6,14-23$.

Stewart, S., \& Dempsey, L. F. (2005). A longitudinal study of baccalaureate nursing students' critical thinking dispositions. Journal of Nursing Education, 44(2), 81.

Theodosiadou, K. (2012). Critical Thinking in the Greek Educational System. Journal of Teaching and Education, 1(3), 253-259.

Tight, M. (2019). Student retention and engagement in higher education. Journal of Further and Higher Education, 1-16.

Tinto, V. (1993). Leaving college: Rethinking the causes and cures of student attrition (2nd ed.). Chicago, IL: University of Chicago Press.

West, R. F., Toplak, M. E., \& Stanovich, K. E. (2008). Heuristics and biases as measures of critical thinking: Associations with cognitive ability and thinking dispositions. Journal of Educational Psychology, 100, 930-941.

Wingate, U. (2007). A framework for transition: Supporting 'learning to learn' in higher education. Higher Education Quarterly, 61(3), 391-405.

Youn, D. K. (1992). Student retention: Many more ideas. College Student Journal, 26(4), 472475 


\section{Appendix}

Academic Self-Concept Scale, Critical Thinking Dispositions Scale, and College Persistence Questionnaire Test-Version 3 (Factor 7: Degree Commitment) - Compiled

The following questionnaire consists of 36 questions. Please respond to the following questionnaire by circling the number $(1,2,3,4,5)$ that best reflects your answer and corresponds to whether you agree with the suggestion made about your academic experience. There are no right or wrong answers. You have briefly 20 minutes for its completion.

Gender: Male / Female

Age:

School / Field of Study:

Grades (If Applicable):

Unique Participant Code:

(Last three surname letters + last three digits of phone number, e.g. DAS834)

DISCLAIMER: Please Note That the Present Questionnaire Is by No Means a Form of Self/Peer Evaluation. It Is Meant to Be Used for the Sole Purposes of This Specific Research.

\begin{tabular}{|c|c|c|c|c|c|c|}
\hline & & $\begin{array}{l}\text { Completely } \\
\text { Disagree }\end{array}$ & Disagree & Unsure & Agree & $\begin{array}{l}\text { Completely } \\
\text { Agree }\end{array}$ \\
\hline 1 & I can follow the lectures easily. & 1 & 2 & 3 & 4 & 5 \\
\hline 2 & I daydream a lot in lectures. & 1 & 2 & 3 & 4 & 5 \\
\hline 3 & $\begin{array}{l}\text { I am able to help my course mates in their } \\
\text { schoolwork. }\end{array}$ & 1 & 2 & 3 & 4 & 5 \\
\hline 4 & I often do my course work without thinking. & 1 & 2 & 3 & 4 & 5 \\
\hline 5 & If I work hard, I think I can get better grades. & 1 & 2 & 3 & 4 & 5 \\
\hline 6 & I pay attention to the lecturers during lectures. & 1 & 2 & 3 & 4 & 5 \\
\hline 7 & Most of my course mates are smarter than I am. & 1 & 2 & 3 & 4 & 5 \\
\hline 8 & I study hard for my tests. & 1 & 2 & 3 & 4 & 5 \\
\hline 9 & My lecturers feel that I am poor in my studies. & 1 & 2 & 3 & 4 & 5 \\
\hline 10 & I am usually interested in my course work. & 1 & 2 & 3 & 4 & 5 \\
\hline 11 & I often forget what I have learned. & 1 & 2 & 3 & 4 & 5 \\
\hline 12 & $\begin{array}{l}\text { I will do my best to pass all the courses this } \\
\text { semester. }\end{array}$ & 1 & 2 & 3 & 4 & 5 \\
\hline 13 & $\begin{array}{l}\text { I get frightened when I am asked a question by the } \\
\text { lecturers. }\end{array}$ & 1 & 2 & 3 & 4 & 5 \\
\hline 14 & I often feel like quitting the degree course. & 1 & 2 & 3 & 4 & 5 \\
\hline 15 & I am good in most of my courses. & 1 & 2 & 3 & 4 & 5 \\
\hline 16 & $\begin{array}{l}\text { I am always waiting for the lecture to end and go } \\
\text { home. }\end{array}$ & 1 & 2 & 3 & 4 & 5 \\
\hline 17 & I always do poorly in course works and tests. & 1 & 2 & 3 & 4 & 5 \\
\hline 18 & $\begin{array}{l}\text { I do not give up easily when I am faced with a } \\
\text { difficult question in my course work. }\end{array}$ & 1 & 2 & 3 & 4 & 5 \\
\hline 19 & $\begin{array}{l}\text { I am able to do better than my friends in most } \\
\text { courses. }\end{array}$ & 1 & 2 & 3 & 4 & 5 \\
\hline 20 & $\begin{array}{l}\text { I am not willing to put in more effort in my course } \\
\text { work }\end{array}$ & 1 & 2 & 3 & 4 & 5 \\
\hline 21 & $\begin{array}{l}\text { I usually try to think about the bigger picture } \\
\text { during a discussion. }\end{array}$ & 1 & 2 & 3 & 4 & 5 \\
\hline 22 & $\begin{array}{l}\text { I often use new ideas to shape (modify) the way I } \\
\text { do things. }\end{array}$ & 1 & 2 & 3 & 4 & 5 \\
\hline 23 & $\begin{array}{l}\text { I use more than one source to find out information } \\
\text { for myself. }\end{array}$ & 1 & 2 & 3 & 4 & 5 \\
\hline
\end{tabular}




\begin{tabular}{|c|c|c|c|c|c|c|}
\hline & & $\begin{array}{l}\text { Completely } \\
\text { Disagree }\end{array}$ & Disagree & Unsure & Agree & $\begin{array}{c}\text { Completely } \\
\text { Agree }\end{array}$ \\
\hline 24 & I am often on the lookout for new ideas. & 1 & 2 & 3 & 4 & 5 \\
\hline 25 & $\begin{array}{l}\text { I sometimes find a good argument that challenges } \\
\text { some of my firmly held beliefs. }\end{array}$ & 1 & 2 & 3 & 4 & 5 \\
\hline 26 & $\begin{array}{l}\text { It's important to understand other people's } \\
\text { viewpoint on an issue. }\end{array}$ & 1 & 2 & 3 & 4 & 5 \\
\hline 27 & It is important to justify the choices I make. & 1 & 2 & 3 & 4 & 5 \\
\hline 28 & $\begin{array}{l}\text { I often re-evaluate my experiences so that I can } \\
\text { learn from them. }\end{array}$ & 1 & 2 & 3 & 4 & 5 \\
\hline 29 & $\begin{array}{l}\text { I usually check the credibility of the source of } \\
\text { information before making judgements. }\end{array}$ & 1 & 2 & 3 & 4 & 5 \\
\hline 30 & $\begin{array}{l}\text { I usually think about the wider implications of a } \\
\text { decision before taking action. }\end{array}$ & 1 & 2 & 3 & 4 & 5 \\
\hline 31 & $\begin{array}{l}\text { I often think about my actions to see whether I } \\
\text { could improve them. }\end{array}$ & 1 & 2 & 3 & 4 & 5 \\
\hline 32 & $\begin{array}{l}\text { My family supports my pursuit of a college degree, } \\
\text { in terms of their encouragement and expectations. }\end{array}$ & 1 & 2 & 3 & 4 & 5 \\
\hline 33 & $\begin{array}{l}\text { At this moment in time, I would say my } \\
\text { commitment to earn a college degree here or } \\
\text { elsewhere is strong. }\end{array}$ & 1 & 2 & 3 & 4 & 5 \\
\hline 34 & $\begin{array}{l}\text { When thinking of the people who mean the most to } \\
\text { me (friends and family), I think they would be } \\
\text { disappointed if I quit school. }\end{array}$ & 1 & 2 & 3 & 4 & 5 \\
\hline 35 & $\begin{array}{l}\text { There are so many things that can interfere with } \\
\text { students making progress toward a degree; feelings } \\
\text { of uncertainty about finishing are likely to occur } \\
\text { along the way. At this moment in time, I am certain } \\
\text { that I will earn a college degree. }\end{array}$ & 1 & 2 & 3 & 4 & 5 \\
\hline 36 & $\begin{array}{l}\text { After beginning college, students sometimes } \\
\text { discover that a college degree is not quite as } \\
\text { important to them as it once was. My intention to } \\
\text { persist in my pursuit of a degree here or elsewhere } \\
\text { is strong. }\end{array}$ & 1 & 2 & 3 & 4 & 5 \\
\hline
\end{tabular}

